nomson

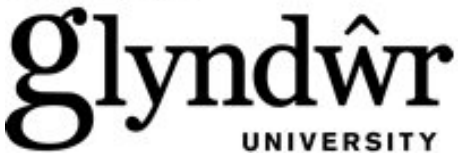

Glyndŵr University

Glyndŵr University Research Online

Aeronautical Engineering

Engineering

4-1-2002

\title{
Flexural and interlaminar shear strength properties of carbon fibre/epoxy composites cured thermally and with microwave radiation
}

\author{
C Nightingale \\ Richard Day \\ GlyndwrUniversity, r.day@glyndwr.ac.uk
}

Follow this and additional works at: http://epubs.glyndwr.ac.uk/aer_eng

Part of the Analytical Chemistry Commons, Catalysis and Reaction Engineering Commons,

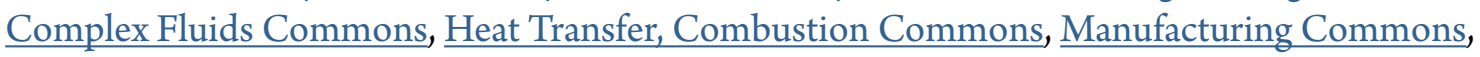
Materials Chemistry Commons, Mechanics of Materials Commons, Membrane Science Commons, Nanoscience and Nanotechnology Commons, Organic Chemistry Commons, Other Chemical Engineering Commons, Other Chemistry Commons, Other Civil and Environmental Engineering Commons, Other Engineering Science and Materials Commons, Other Materials Science and Engineering Commons, Petroleum Engineering Commons, Physical Chemistry Commons, Polymer and Organic Materials Commons, Polymer Chemistry Commons, Polymer Science Commons, $\underline{\text { Structural Engineering Commons, Structural Materials Commons, and the Thermodynamics }}$ Commons

\section{Recommended Citation}

Nightingale C. \& Day, R.J. (2002) 'Flexural and interlaminar shear strength properties of carbon fibre/epoxy composites cured thermally and with microwave radiation'. Composites Part A: Applied Science and Manufacturing, Vol 33, Issue 7, pp. 1021-1030.

This Article is brought to you for free and open access by the Engineering at Glyndŵr University Research Online. It has been accepted for inclusion in Aeronautical Engineering by an authorized administrator of Glyndŵr University Research Online. For more information, please contact d.jepson@glyndwr.ac.uk. 


\title{
Flexural and interlaminar shear strength properties of carbon fibre/epoxy composites cured thermally and with microwave radiation
}

\begin{abstract}
The ease of heating an epoxy resin with microwaves depends, among other factors, on the dielectric properties of its components at the frequency of the radiation used. The majority of the papers published on the microwave curing of reinforced epoxy resin composites have used widely available DGEBA type resins and amine hardeners such as 4,4'-diaminodiphenylsulphone (DDS). This paper investigates the use of two epoxy systems where the choice of resin and hardener was based on their measured dielectric loss factors. System 1 contained a resin and hardener with higher loss factors than those used in System 2. The two systems were formulated with polyetherimide (PEI) as a toughening agent. Unidirectional carbon fibre prepregs were prepared from both systems. Composites were laid up from these prepregs which were then cured in three different ways: autoclave curing, partial autoclave curing followed by microwave post-curing, and microwave curing. System 1 composites had greater flexural properties and interlaminar shear strengths than System 2 composites when autoclave cured. Flexural properties and interlaminar shear strengths were greater for System 2 in the microwave post-cured composites. When fully microwave cured the properties were similar. In the microwave cured composites the flexural and interlaminar shear properties were influenced by the structure of the phase separated PEI and the void content.
\end{abstract}

Keywords

fibres, carbon fibres, mechanical properties, mechanical testing, microwave, epoxy resin

\section{Disciplines}

Analytical Chemistry | Catalysis and Reaction Engineering | Chemical Engineering | Chemistry | Complex Fluids | Engineering | Engineering Science and Materials | Heat Transfer, Combustion | Manufacturing | Materials Chemistry | Materials Science and Engineering | Mechanical Engineering | Mechanics of Materials | Membrane Science | Nanoscience and Nanotechnology | Organic Chemistry | Other Chemical Engineering | Other Chemistry | Other Civil and Environmental Engineering | Other Engineering Science and Materials | Other Materials Science and Engineering | Petroleum Engineering | Physical Chemistry | Polymer and Organic Materials | Polymer Chemistry | Polymer Science | Structural Engineering | Structural Materials | Thermodynamics

\section{Comments}

Copyright (C) 2002 Elsevier. All rights reserved.

This is the author's final version of the work after peer review. The article was originally published in Composites Part A: Applied Science and Manufacturing in 2002 by Elsevier. The full published article can be found at http://dx.doi.org/10.1016/S1359-835X(02)00031-3 on the publisher's website http://sciencedirect.com 


\title{
FLEXURAL AND INTERLAMINAR SHEAR STRENGTH PROPERTIES OF CARBON FIBRE/EPOXY COMPOSITES CURED THERMALLY AND WITH MICROWAVE \\ RADIATION
}

\author{
C Nightingale \& R J Day* \\ Manchester Materials Science Centre, UMIST \& University of Manchester, Grosvenor Street, \\ Manchester, UK, M1 7HS
}

\begin{abstract}
The ease of heating an epoxy resin with microwaves depends, among other factors, on the dielectric properties of its components at the frequency of the radiation used. The majority of the papers published on the microwave curing of reinforced epoxy resin composites have used widely available DGEBA type resins and amine hardeners such as 4,4'-diaminodiphenylsulphone (DDS). This paper investigates the use of two epoxy systems where the choice of resin and hardener was based on their measured dielectric loss factors. System 1 contained a resin and hardener with higher loss factors than those used in System 2. The two systems were formulated with polyetherimide (PEI) as a toughening agent. Unidirectional carbon fibre prepregs were prepared from both systems. Composites were laid up from these prepregs which were then cured in three different ways: autoclave curing, partial autoclave curing followed by microwave post-curing, and microwave curing. System 1 composites had greater flexural properties and interlaminar shear strengths than System 2 composites when autoclave cured. Flexural properties and interlaminar shear strengths were greater for System 2 in the microwave post-cured composites. When fully microwave cured the properties were similar. In the microwave cured composites the flexural and interlaminar shear properties were influenced by the structure of the phase separated PEI and the void content.
\end{abstract}

Keywords: (A) Polymer matrix composites, Microwave, (D) Mechanical testing, 


\section{Introduction}

Microwave curing of epoxy resins has many potential advantages over thermal curing: energy saving; lower operating costs; reduced time for complete cure; more uniform cure; improved mechanical/physical properties; higher efficiency and increased throughput; increased process control; reduced degradation $[1,2]$. Similar advantages have been observed with the microwave curing of epoxy resin composites [310], as well as improved interfacial bonding during the cure of glass fibre composites [3, 9, 11-15], and improved mechanical properties for carbon fibre composites [4, 5, 9]. The production of thermoset composite materials usually requires the maximisation of the glass transition temperature, $T_{\mathrm{g}}$, and the minimisation of the void content $[7,8,14,16,17]$. Cure procedures are designed so that the glass transition temperature is maximised, i.e. during cross-linking vitrification occurs after the material has fully gelled and the glass transition temperature exceeds the cure temperature [3, 6]. Since many resin systems are susceptible to moisture absorption, the formation and growth of voids during cure can lead to the presence of permanently trapped voids inside the cured composites [16]. To maximise the mechanical strength of the composite the voids should be minimised. Uncured resins may contain 3-5\% absorbed water and this amount, when converted into voids, could occupy a considerable volume within the resin due to the high mole percentage of water. The high dielectric loss of water would also result in a rapid rise in temperature within its vicinity when heated using microwaves, leading to the rapid diffusion of water vapour from the resin into existing and nucleating voids, which would significantly increase void growth [17]. The number of voids can be reduced by physically transporting them out of the resin/fibre network through the use of vacuum bagging $[16,17]$. This technique, however, has two limiting factors caused by the partial pressure of volatiles in the system, and changes in the resin viscosity during the curing process. The vacuum achieved in a bagging arrangement is generally $0.67-1.33 \mathrm{kPa}$, depending on the viscosity and volatility of the resin system $[16,17]$. If a higher vacuum is used, excessive resin extraction would occur, resulting in resin starvation within the component. If the resin viscosity is too low excessive resin may be removed, again resulting in resin starvation within the component fibre 
network. If the viscosity is too high air removal is impeded. For a given component, therefore, there is a range of viscosity values within which voids can be removed effectively, without excessive resin removal $[16,17]$.

Previous research on the flexural and interfacial properties of composites cured using microwave heating has concentrated on glass reinforcement $[3,7,8,12,13,15,18]$. Composites consisting of 12 plies of 0/90 cross-woven E glass fibres in a DGEBA resin, measuring $150 \mathrm{~mm}$ by $100 \mathrm{~mm}$ by a maximum of 13 $\mathrm{mm}$ have been microwave cured in a vacuum bag at $2.45 \mathrm{GHz}$. Powers of $400 \mathrm{~W}$ and $600 \mathrm{~W}$ were used to achieve the maximum flexural strength, measured by four point bending, after 20 and $12 \mathrm{~min}$, respectively. Maximum flexural strength was obtained in thermally cured samples after 4 hours. Using four point bending tests it was found that the flexural moduli for microwave cured specimens were greater than those obtained for thermally cured samples [3].

The presence of graphite fibres in a composite can affect the coupling of the microwave energy [19, 20]. This can lead to problems such as arcing and local hot spots which have resulted in burning of the matrix $[19,20]$. Carbon fibre/epoxy composites (Hercules AS4-3502) have been processed in a $\mathrm{TE}_{112}$ mode cylindrical cavity at $2.45 \mathrm{GHz}$ in an attempt to understand the coupling characteristics. The graphite fibre orientation in the specimen influenced the power absorbed by the composite [21]. When the fibre orientation was parallel to the electric field, the centre of the specimen showed a greater temperature increase than the outer edges, since these were located at the highest electric field. When the fibre orientation was perpendicular to the electric field the coupling efficiency at the outer edges of the sample decreased, while in the centre it increased dramatically. The stacking sequence was also found to influence the energy coupling of the composite [21]. For a $90^{\circ} / 0^{\circ}$ cross-ply laminate with the top ply perpendicular to the electric field, the temperature profile obtained was not an average of the profiles for $0^{\circ}$ and $90^{\circ}$. Sample dimensions were also found to affect the power absorption [21]. When the dimensions of the square graphite/epoxy samples were increased from $2.54 \mathrm{~cm}$ to $5.08 \mathrm{~cm}$ and the 
samples were placed with the fibre direction parallel to the electric field, the difference between the temperature at the centre and the outer edges lowered with increasing dimensions. The largest sample showed a reversal of the energy coupling characteristic, in that the temperature rise in the sample was less than at the outer edges [21].

The aim of this work was to compare the mechanical properties of two types of carbon fibre/epoxy composites, where the resin and hardener of the first system had dielectric loss factors which were considerably higher than those of the second system. The flexural properties and interlaminar shear strength properties of two composites were compared after curing thermally and with microwave radiation. The void contents were also measured and compared for the different processing routes.

\section{$2 \quad$ Experimental}

\subsection{Resin Composition}

The dielectric permittivity and loss factors of potential resin constituents were measured in a cylindrical brass cavity resonating in the $\mathrm{TM}_{010}$ mode. Details of the measurement procedure and the dielectric properties of these materials are given elsewhere [22]. From these results two resin systems were formulated. System 1 consisted of a triglycidyl $p$ aminophenol (TGPAP) resin with 4,4'diaminodiphenylsulphone (DDS) hardener, with dielectric loss factors of 1.36 and 0.87 , respectively. The ratio of resin to hardener used was 1:0.7 and this was determined by finding the ratio at which the $\mathrm{T}_{\mathrm{g}}$ was maximised [22]. System 2 consisted of a tetraglycidyldiaminodiphenylmethane (TGDDM) resin with a tetrafunctional amine hardener. The loss factors of these components were 0.57 and 0.33 , respectively. The ratio of resin to hardener used was 1:0.9 [22] and this was also determined by finding the composition which gave the maximum $\mathrm{T}_{\mathrm{g}}$. Both of the systems were formulated with $15 \%$ wt polyetherimide (PEI) as the toughening agent, which had a loss factor of 0.42 . The systems were then 
made into unidirectional prepregs with Tenax HTA $12 \mathrm{~K}$ carbon fibre to give a $66 \%$ volume fraction of fibres [22].

\subsection{Curing Procedures}

\subsubsection{Autoclave Curing}

For the autoclave curing a composite consisting of 16 plies measuring $130 \mathrm{~mm}$ by $100 \mathrm{~mm}$ with the fibres in the $0^{\circ}$ direction parallel to the $100 \mathrm{~mm}$ side was prepared. The composites were then placed in a vacuum bag in an autoclave and cured by heating at $2{ }^{\circ} \mathrm{C} / \mathrm{min}$ to $180{ }^{\circ} \mathrm{C}$ and then holding for two hours at a pressure of $700 \mathrm{kPa}$. These composites were prepared in order to compare the properties with data for similar commercial materials[22] and to enable a comparison with $(0 / 90)_{\mathrm{s}}$ samples.

\subsubsection{Microwave Post-curing}

Composites consisting of 16 plies measuring $300 \mathrm{~mm}$ by $300 \mathrm{~mm}$ with the fibres in a $\left(0 / 90^{\circ}\right)_{8}$ arrangement were prepared for the microwave post-curing experiments. They were then placed in a vacuum bag and cured in an autoclave for three and a half hours at $130{ }^{\circ} \mathrm{C}$. On removal from the autoclave the composites were cut up into eight panels measuring $80 \mathrm{~mm}$ by $80 \mathrm{~mm}$. The procedure was intended to partially cure the samples, so that microwave curing without the application of pressure could be explored as a method of cycle time reduction. The lay-up of the plies was selected because it was anticipated that this would be more difficult to cure than a unidirectional lay-up due to attenuation of both polarisations of the electromagnetic waves.

The microwave oven used in the post-curing and full microwave curing experiments was a Moulinex Quickchef 1000QE domestic oven with five power settings. Each power cycle consisted of a time period 
where the power was on followed by a period where the power was off and the timings are given in Table 1. The longest microwave post-curing schedule used for both composites was 20 minutes on power setting three followed by 20 minutes on power setting four. The times used in this curing schedule were varied to observe the effect on the degree of cure and mechanical properties, and the settings used are shown in Table 2.

\subsubsection{Full Microwave Curing}

A vacuum bag arrangement could not be used for the full microwave curing process because the presence of the carbon fibres caused a spark as soon as the power was switched on. The spark punctured the vacuum bag resulting in the loss of vacuum and pressure on the composite. To overcome this an assembly consisting of two PTFE plates was then used, which was clamped together by four PTFE sleeves which slid around the plates. This ensured that there was some pressure on the laminate as it was curing. The assembly is shown in Figure 2. For both systems, ten composites were laid up, each samples consisting of eight layers of prepreg with the fibres in the $0^{\circ}$ direction. Of the ten composites prepared, five were heated in the microwave with the fibre direction parallel to the radius of the microwave turntable. The other five laminates were heated with the fibre direction perpendicular to the radius of the turntable. The turntable rotated during the heating process, as normal. Microwave heating was carried out initially on a test sample of each composite to determine the cure time required to achieve full cure, as measured by DSC [22]. System 1 composites were microwave cured for 60 minutes on power setting 2, and composites of System 2 were cured for 40 minutes on power setting 2, both with a $500 \mathrm{ml}$ water load to absorb some of the power. 


\subsection{Flexural and Interlaminar Shear Strength Testing}

The flexural properties were determined by the four-point bend test, based on ASTM D 790-95a [23], and the tests were conducted on simply supported beams of constant cross-sectional area. The standard describes two test procedures. Procedure A is used for samples which fail at comparatively small deflections and is generally used to determine flexural modulus. Procedure B is used for samples which fail at comparatively large deflections and is generally used to determine flexural strength. Both of these procedures were used in this study. During the tests an Instron 1185 mechanical testing machine with a 5 $\mathrm{kN}$ load cell was used. The test samples were of length $80 \mathrm{~mm}$ and width $10 \mathrm{~mm}$, and the thickness of the samples varied between 1 and $2 \mathrm{~mm}$. The support span-to-depth ratio used was 16 to 1 . The crosshead speed for Procedure A was $2 \mathrm{~mm} / \mathrm{min}$, and for Procedure B it was $20 \mathrm{~mm} / \mathrm{min}$. The flexural strength, $S$, was calculated [23] from Equation 1 using the data collected at a crosshead speed of $20 \mathrm{~mm} / \mathrm{min}$.

$$
S=\left(\frac{3 P L}{4 b d^{2}}\right)\left[1-\left(\frac{10.91 D d}{L^{2}}\right)\right]
$$

Eq. 1

where $S=$ maximum stress in the outer fibres throughout the load span (MPa), $P=$ load at the moment of break $(\mathrm{N}), L=$ support span $(\mathrm{mm}), b=$ width of beam $(\mathrm{mm}), d=$ depth of beam $(\mathrm{mm}), D=$ midspan deflection (mm). The flexural modulus, $E_{B}$, was calculated [23] from Equation 2 using the data collected at a crosshead speed of $2 \mathrm{~mm} / \mathrm{min}$.

$$
E_{B}=\frac{0.17 L^{3} m}{b d^{3}}
$$

where $E_{B}=$ modulus of elasticity in bending $(\mathrm{MPa})$ and $m=$ slope of the tangent to the initial straight-line portion of the load-deflection curve ( $\mathrm{N} / \mathrm{mm}$ of deflection). 
In order to determine the interlaminar shear strength the short beam shear test was used. The jig consisted of steel rollers of $5.0 \mathrm{~mm}$ diameter for the load nose and $3.4 \mathrm{~mm}$ diameter for the side supports [24]. Measurements were carried out on the microwave post-cured and fully microwave cured samples using an Instron 4301 mechanical testing apparatus contolled by Instron Series IX Automated Materials Tester software (version 7.50.00). The microwave cured composites consisted of eight prepreg layers, whereas the post-cured and fully autoclaved samples consisted of 16 layers. The steel roller for the load nose was, therefore, replaced with one with a diameter of $3 \mathrm{~mm}$ during the tests on the microwave cured samples. Interlaminar shear strength (ILSS) was determined [24] from Equation 3.

$$
I L S S=\frac{3 P}{4 b d}
$$

Eq. 3

where $b$ is the specimen width $(\mathrm{mm}), d$ is the thickness $(\mathrm{mm})$, and $P$ is the failure load $(\mathrm{N})$.

The void content in the composites was determined by image analysis. The composites were mounted in a polyester resin and then polished using Bueller Metaserve $6 \mu \mathrm{m}$ and $1 \mu \mathrm{m}$ diamond polishing wheels. A sample was placed under a light microscope and an image was focused and acquired using a video camera. A light pen was then used at a chosen magnification to highlight the voids in the image, and then void percentage was calculated by dividing the area of the highlighted voids by the area of the of the image on the screen at the correct magnification. This procedure was repeated ten times at different positions to give an average void content for each sample. 


\subsection{Microscopy of Matrix Fracture Surfaces}

Scanning electron microscopy was used to examine the morphology of the two systems containing PEI as the toughening agent. This was because the PEI dissolves in the resin initially and then phase separates out during cure, hence the size of the particles is related to the extent of the cure [25]. Samples cured thermally and by microwave radiation were compared, in order to establish whether the phase separation of the toughening particles occurred in the same way for both curing methods. In order to examine the resins, a fracture surface was required. Partially cured samples were brittle hence a fracture surface was obtained by manually snapping the samples in two. Fully cured samples were much tougher, thus a small notch was cut into the samples with a junior hacksaw, then the sample was held in a vice and hit with a hammer to propagate a crack from the notch tip. Samples of System 1/PEI and System 2/PEI which had been thermally cured for $90 \mathrm{~min}$ at $130{ }^{\circ} \mathrm{C}$ followed by 15 and $120 \mathrm{~min}$ at $180{ }^{\circ} \mathrm{C}$ were examined. These samples had extents of cure greater than $90 \%$. Samples of System 2/PEI which had been microwave cured for the two longest times (35 and 40 minutes) before charring of the resin occurred, with extents of cure of approximately $35 \%$ were also examined. It was not possible to examine thermally cured samples with the equivalent extents of cure as these samples were not in the solid state, hence fracture samples could not be obtained.

\section{$3 \quad$ Results and Discussion}

\subsection{Flexural Properties and Interlaminar Shear Strengths}

Figures 3 and 4 show the flexural modulus and strength of microwave post-cured composites. Also shown on the figures is the average flexural strength and modulus values for autoclaved composites for comparison. One sample was tested for each curing time. There does not appear to be any dependence of the properties with curing time, but this is expected, as the effect of the fibres will be more dominant in 
these tests. The lay-up of the autoclaved samples was unidirectional, while the microwave post-cured samples were $(90 / 0)_{\mathrm{s}}$ hence it would be expected that the flexural modulus for a fully microwave post cured sample would be approximately half that of the autoclaved samples. Figure 3 shows that the flexural moduli are as expected. The flexural moduli of the autoclaved composites is virtually the same, regardless of the resin system and the flexural moduli of the microwave post cured samples are approximately one half of the values for the autoclave cured composites.

With microwave post-curing System 2 composites gave better strength and modulus values than System 1 composites, which was the opposite behaviour to that observed for the fully autoclaved composites. Table 3 gives the flexural strengths and moduli of microwave cured composites together with the interlaminar shear strengths and from this it can be noted that the orientation of the specimen on the turntable did not affect the results obtained, except for the ILSS of system 1. The interlaminar shear strengths for autoclaved composites at 22 and $81{ }^{\circ} \mathrm{C}$ are given in table 4 . The interlaminar shear strengths were higher at room temperature than at $82{ }^{\circ} \mathrm{C}$ for both types of composites. Higher flexural strengths were observed in System 1 composites than in System 2. The values obtained were comparable to those published for similar carbon fibre composites [26]. Figure 5 shows the interlaminar shear strengths of microwave post-cured composites as a function of post cure time. The interlaminar shear strengths were greater in the microwave post-cured System 2 composites than in the System 1 composites. The superior ILSS performance of System 2 composites was due to the lower void content, which will be discussed later. The interlaminar shear strengths were greater in the fully microwave cured composites (Table 3) than in the microwave post-cured composites (figure 4). This result was unexpected since the microwave-cured composites were processed without a vacuum. 


\subsection{Fracture surfaces of the matrices}

When PEI is used to toughen epoxy resin systems the PEI dissolves initially and then precipitates out during the curing reaction to form a two-phase co-continuous structure of rigid thermosetting polymer and ductile thermoplastic polymer [25]. Thermodynamics, kinetics and cure rates control the phase separation of systems modified by the addition of thermoplastic polymers [25]. Thermodynamic changes are the primary impetus for phase separation and kinetics governs the extent to which the system follows the equilibrium path as curing progresses. The rate of network formation determines whether thermodynamics or kinetics will dominate the final outcome of phase separation [25]. For a TGDDM/DDS system with a PEI content of less than $20 \mathrm{phr}$, thermally cured for $2 \mathrm{~h}$ at $140{ }^{\circ} \mathrm{C}$ followed by $2 \mathrm{~h}$ at $190^{\circ} \mathrm{C}$, the morphology of the system consists of spherical inclusions of PEI dispersed in the epoxy matrix [27]. For the same loading of PEI but using cure schedule of 88 hours at $70{ }^{\circ} \mathrm{C}$ a cocontinuous phase structure was obtained because curing at a low temperature for a long time results in the gelation of the resin mixture in the early stages of phase separation [27]. Figures 6 and 7 show the fracture surfaces of PEI toughened System 1 and System 2 resins, respectively, after thermal curing for 90 minutes at $130{ }^{\circ} \mathrm{C}$ and then 2 hours at $180{ }^{\circ} \mathrm{C}$. For System 1 some evidence of ductility was observed, but for System 2 only the separate domains of PEI were present and the fracture surface appeared more brittle[22]. DSC measurements showed under the same curing conditions the extent of cure increased faster in System 1 than in System 2, i.e. System 1 cured at a quicker rate [22]. This was due to the fact that the epoxy in System 1 was trifunctional, compared with the tetrafunctional resin used in System 2. Furthermore, the molecular weight of the hardener used in System 2 was much larger than that of the hardener used in System 1, and the amine group was hindered. Hence in System 1 gelation probably occurred earlier on in the phase separation. The matrices of autoclaved System 1 and System 2 composites are expected to be similar to those observed in Figures 6 and 7. It has been found in PEI toughened systems that improvements in the flexural strengths are more pronounced with a co-continuous morphology because the toughening mechanism of PEI modified resins is the ductile yielding of the PEI 
[27]. This would explain why the flexural strength (figure 4) and ILSS (table 4) of autoclave cured System 1 composites are superior to those of System 2 composites.

Figure 8 shows the fracture surface of toughened System 2 after microwave curing, and there is evidence of some discrete PEI domains as well as co-continuous structures. A co-continuous structure can be obtained by fixing the morphology in the early stages of phase separation by curing for longer at lower temperatures[22]. In the present study it is evident that in System 2 thermal curing under the conditions employed gave rise to discrete PEI domains and a brittle fracture surface ( figure 7) whereas microwave curing gave some co-continuous areas as well. Unfortunately microwave curing of the System 1 matrix was not successful, and thus its fracture surface could not be examined to look for evidence of phase separation. The results of flexural bending measurements on the System 1 composites, however, suggest that microwave curing has also resulted in a co-continuous structure to a greater extent than in system 2

\subsection{Void Content}

Table 4 shows the results of the void content measurements. Figures 9 and 10 illustrate that the autoclave cured composites contained very few voids $(0.1 \%)$ as expected since both pressure and a vacuum had been applied during cure. Microwave post-cured samples had void contents of less than $2 \%$, and the values obtained were all similar. This indicated that the autoclave part of the cure cycle of the composites had succeeded in removing most of the voids before post-curing was carried out in the microwave. An example of a cross section is shown in Figure 11. The increase in the void content may partly account for the difference in flexural strength between the autoclaved and microwave post cured samples.

The microwave cured composites had a considerable number of voids, with System 1 having a greater number than System 2, as shown in Figures 12 to 15 . Void contents of $19.3 \%$ and $19.9 \%$ for System 1 composites cured with parallel and perpendicular fibre orientations, respectively were obtained by image analysis. The void contents for System 2 composites with parallel and perpendicular fibre orientations 
were $8.9 \%$ and $12.0 \%$, respectively. Figures 12 to 15 illustrate that the voids in microwave cured System 1 composites were larger than those for System 2 composites, and in places the voids joined together. There was also a slightly lower void content in samples cured with the fibre direction parallel to the radius of the turntable. At lower magnifications in the microwave cured composites, the layers of prepreg used to make up the composite could be distinguished. The microwave cured composites were processed without the use of a vacuum and under considerably less pressure than the other two types, hence the void content in these laminates was higher. The flexural strengths and moduli of the microwave cured composites were, however, comparable to those cured thermally. Since the resin appears to cure in the same manner regardless of whether thermal or microwave processing conditions are employed [26], the fact that fully microwave cured composites with a high void content exhibited better flexural properties than composites post-cured with microwaves may be because better interfacial properties are achieved with microwave cure than with thermal cure [28]. This has been reported previously for glass fibre/epoxy composites by using single fibre pull-out tests $[3,12-16]$ and in carbon fibre/epoxy composites using Raman spectroscopy [28].

\section{Conclusions}

Resin systems have been developed specifically to examine the effect of microwave cure and to understand formulation issues. The systems were developed initially from the dielectric properties of their components[22] and also incorporated a thermoplastic toughening agent. Carbon fibre prepregs have been made from the two resin systems and microwave cured to produce composites. Autoclave cured composites had the best flexural and ILSS properties followed by the microwave cured composites. Composites that were partially autoclave cured and then post-cured with microwaves had the worst flexural and ILSS properties. The void content of the microwave-cured composites was high, compared with the fully and partially cured composites. This is a direct result of the low applied pressure during cure compared to the autoclave technique used for the other samples. Higher pressure, therefore, is 
essential to produce void free composites. The mechanical properties of microwave cured composites were nevertheless better than for the microwave post-cured composites, despite their larger void content. This suggests that microwave curing, under the correct conditions of pressure and vacuum, could produce composites with comparable mechanical properties to autoclave cured composites but in a much shorter time.

\section{Acknowledgements}

The authors wish to acknowledge the support for this project from Hexcel Composites Limited. CN wishes to thanks to EPSRC for their financial support.

\section{References}

1. WARD T.C., CHEN M, Basic Ideas of Microwave Processing of Polymers. Abstracts of Papers of the American Chemical Society, 203, Part 3, (1992) 170-PMSE.

2. WEI J, THOMAS B, HAWLEY M. C., Scale-Up Study Of Microwave Heating Of Epoxy In Tuneable Cavities. $37^{\text {th }}$ International SAMPE Symposium, (1992) 929-943.

3. BOEY F. Y. C., LEE T. H., Electromagnetic Radiation Curing of an Epoxy/Fibre Glass Reinforced Composite. Radiation Physics and Chemistry, 38 (1991) 419-423.

4. HAWLEY M. C., WEI J., Processing of Polymers and Polymer Composites in a Microwave Applicator. Materials Research Society Symposium Proceedings, 189 (1991) 413-420.

5. WEI J., HAWLEY M. C., JOW J., DELONG J. D., Microwave Processing of Crossply Continuous Graphite Fiber/Epoxy Composites. SAMPE Journal, 27 (1991) 33-39.

6. BOEY F. Y. C., LEE W. L., Microwave Radiation Curing of a Thermosetting Composite. J. Mat. Sci. Lett. 9 (1990) 1172-1173. 
7. BOEY F. Y. C., Techniques in the Microwave Processing of Thermoset Composite Using a High Pressure Autoclave. Proceedings of the $23^{\text {rd }}$ International SAMPE Conference, (1991) 15-24.

8. BOEY F. Y. C., GOSLING I., LYE S. W., High Pressure Microwave Curing Process for an Epoxy Matrix/Glass Fibre Composite. J. Mats Proc. Tech., 29 (1992) 311-319.

9. PAUlAUSKAS F. L., MEEK T. T., Processing of Thermoset Prepreg Laminates Via Exposure to Microwave Radiation. Mats Res. Soc. Symp. Proc., 347 (1994) 743-751.

10. LYE S. W., BOEY F. Y. C., PC-Based Monitoring and Control System for Microwave Curing of Polymer Composites. Mats \& Manuf. Processes, 9 (1994) 851-868.

11. BAI S. L., DJAFARI V., Interfacial Properties of Microwave Cured Composites. Composites, 26, (1995) 645-651.

12. YUE C. Y., BOEY F. Y. C., The Effect of Microwave and Thermal Curing on the Interfacial Properties of an Epoxy/Glass Composite. $2^{\text {nd }}$ International Conference on the Deformation and Fracture of Composites, (1993) 12.1-12.8.

13. YUE C. Y., LOOI H. C., Influence of Thermal and Microwave Processing on the Mechanical and Interfacial Properties of a Glass/Epoxy Composite. Composites, 26 (1995) 767-773.

14. BOEY F. Y. C., Humidity and Autoclave Pressure Effect on the Interfacial Shear Strength of a Microwave Cured Epoxy-Glass Fibre Composite. Polymer Testing, 14 (1995) 471-477.

15. BOEY F. Y. C., YUE C., Interfacial Strength of a Microwave Cured Epoxy-Glass Composite. $J$. Mats Sci. Lett., 10 (1991) 1333-1334.

16. BOEY F. Y. C., Effect of Moisture Content on the High Pressure Microwave Curing of a Thermoset Fiber Reinforced Composite. Pol. Mats. Sci. \& Eng., 66 (1992) 422-423.

17. BOEY F. Y. C., LYE S. W., Void Reduction in Autoclave Processing of Thermoset Composites. Part 2: Void Reduction in a Microwave Curing Process. Composites, 23 (1992) 266-270.

18. AGRAWAL R. K., DRZAL L. T., Effects Of Microwave Processing On Fibre/Matrix Adhesion In Composites. J. Adhesion, 29 (1989) 63-79. 
19. LEE W. I., SPRINGER G. S., Interaction of Electromagnetic Radiation with Organic Matrix Composites. J. Comp. Mats., 18 (1984) 357-386.

20. LEE W. I., SPRINGER G. S., Microwave Curing of Composites. J. Comp. Mats., 18 (1984) 387409.

21. CHEN Y. F., LEE C. Y. C., Coupling of Microwave Energy with Carbon Reinforced Composites. Abstracts of Papers of the ACS, 197 (1989) 149-PMSE.

22. NIGHTINGALE C, Microwave Assisted Curing of Epoxy Resins and Composites. PhD Thesis, University of Manchester Institute of Science and Technology, 2000.

23. ASTM D790-95a, Standard Test Methods for Flexural Properties of Unreinforced and Reinforced Plastics and Electrical Insulating Materials (1995).

24. ASTM D2344-84(1995), 'Standard Test Method for Apparent Interlaminar Shear Strength of Parallel Fiber Composites by Short-Beam Method' (1995).

25. CUI J., YU Y., CHEN W., LI S., Studies on the Phase Separation of Polyetherimide-Modified Epoxy Resin, 2a) Effect of Molecular Weight on the Structure Formation. Macromol. Chem. \& Phys., 198 (1997) 3267-3276.

26. Hexcel Composites Ltd, 'Prepreg Technology' (1997).

27. CHO J. B., HWANG J. W., AN J. H., PARK C. E., Effects Of Morphology On Toughening Of Tetrafunctional Epoxy Resins With Poly(etherimide). Polymer, 34 (1993) 4832-4836.

28. DAY R. J., SAMOLADAS E., Micromechanics of Model Carbon Epoxy Composites Cured Using Microwave Heating. Sci. \& Eng. of Comp. Mats, 7 (1998) 23-50. 


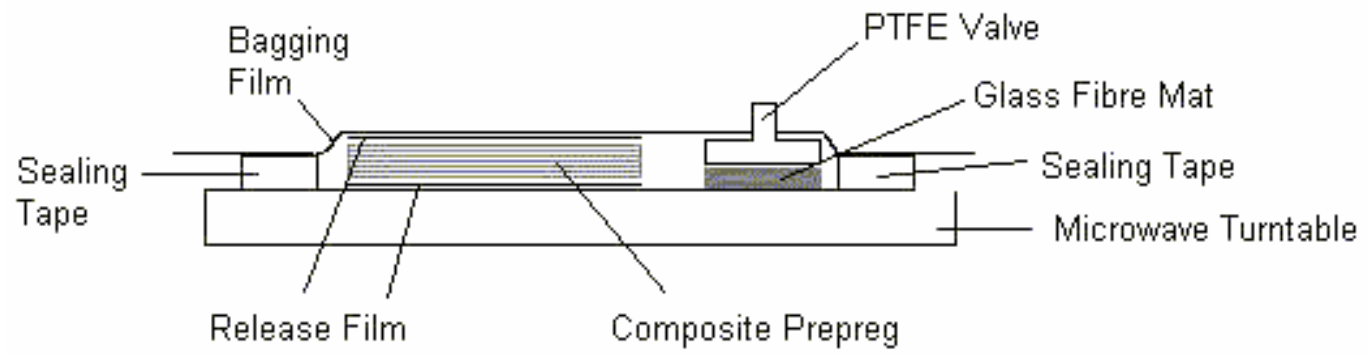

Figure 1. Microwave vacuum bagging arrangement.

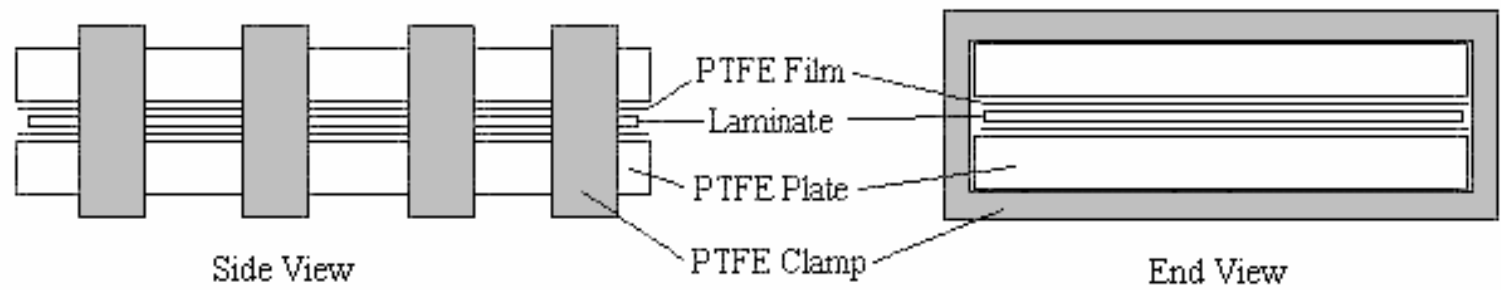

Figure 2. Schematic diagram of the PTFE clamping arrangement

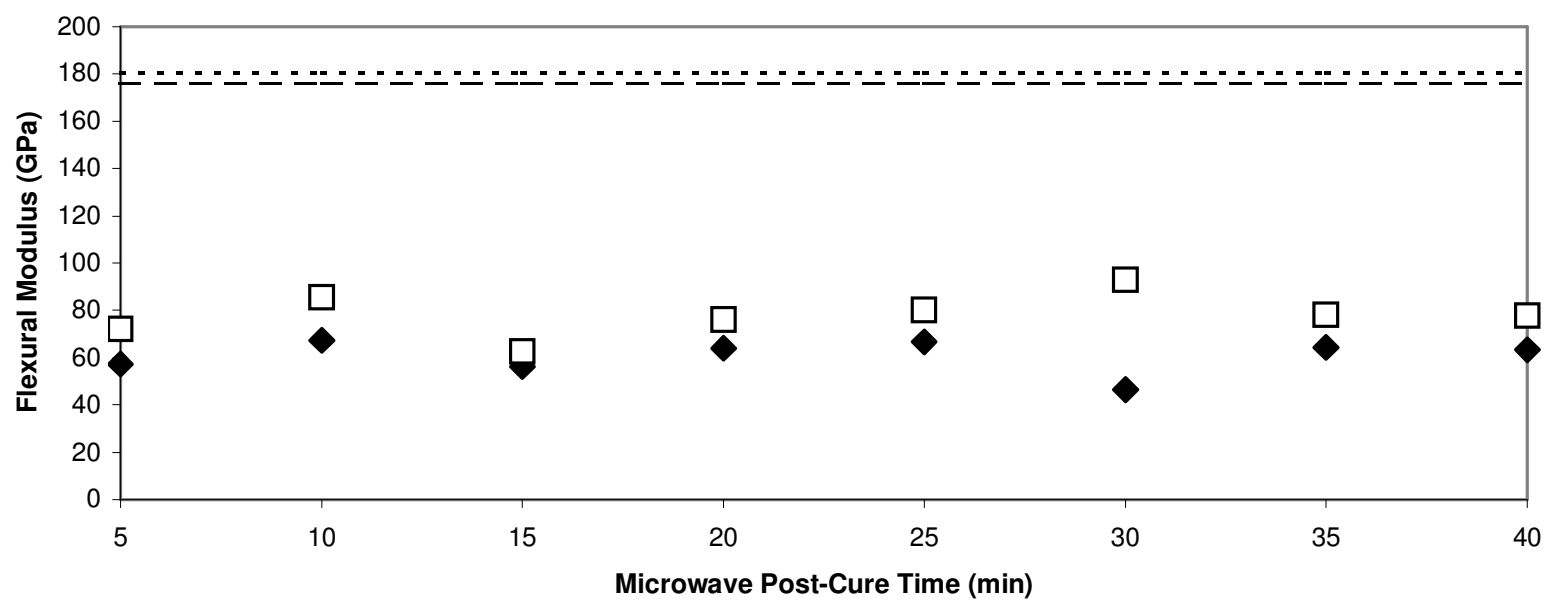

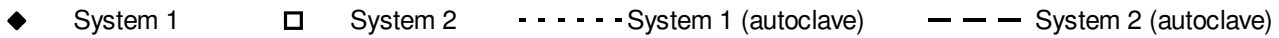

Figure 3. Flexural modulus of microwave post-cured composites 


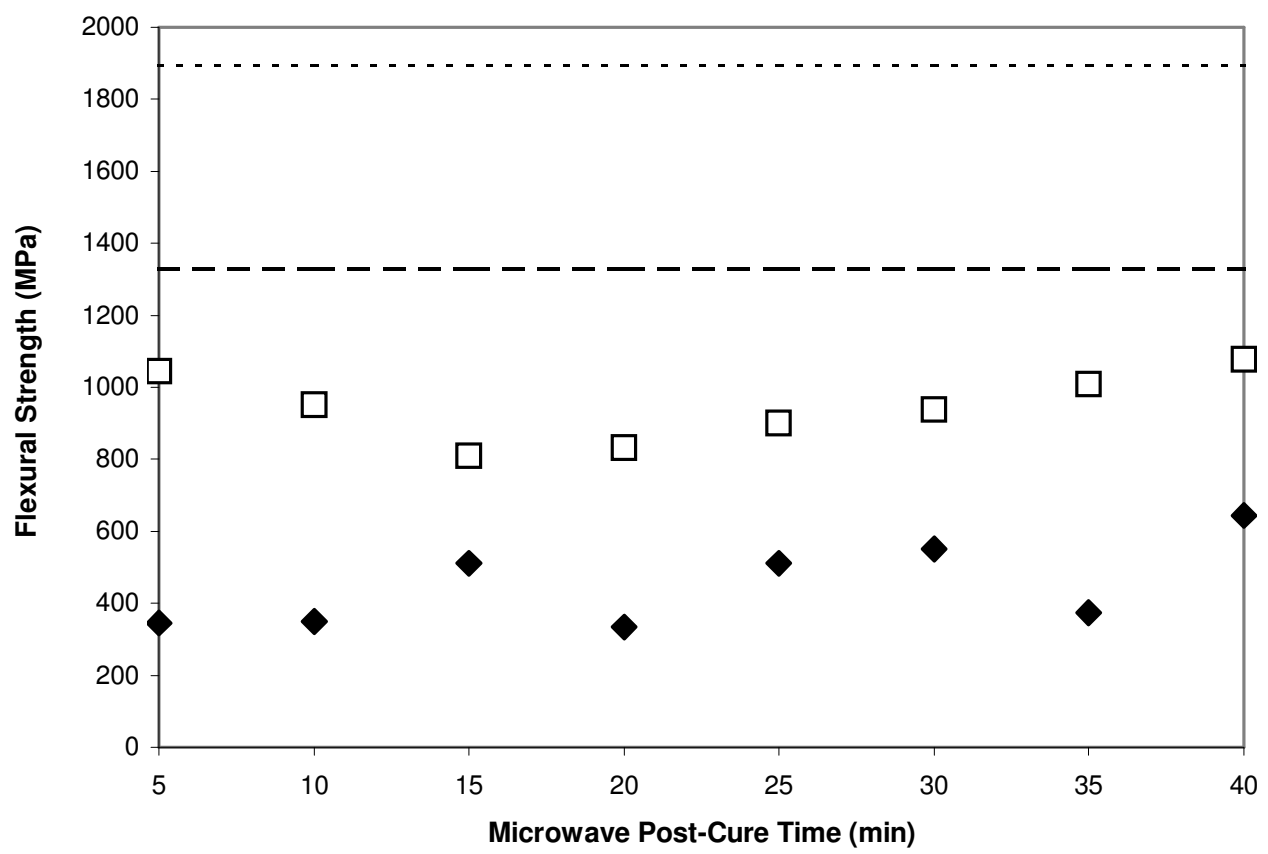

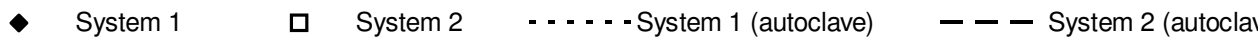

Figure 4. Flexural strength of microwave post-cured composites

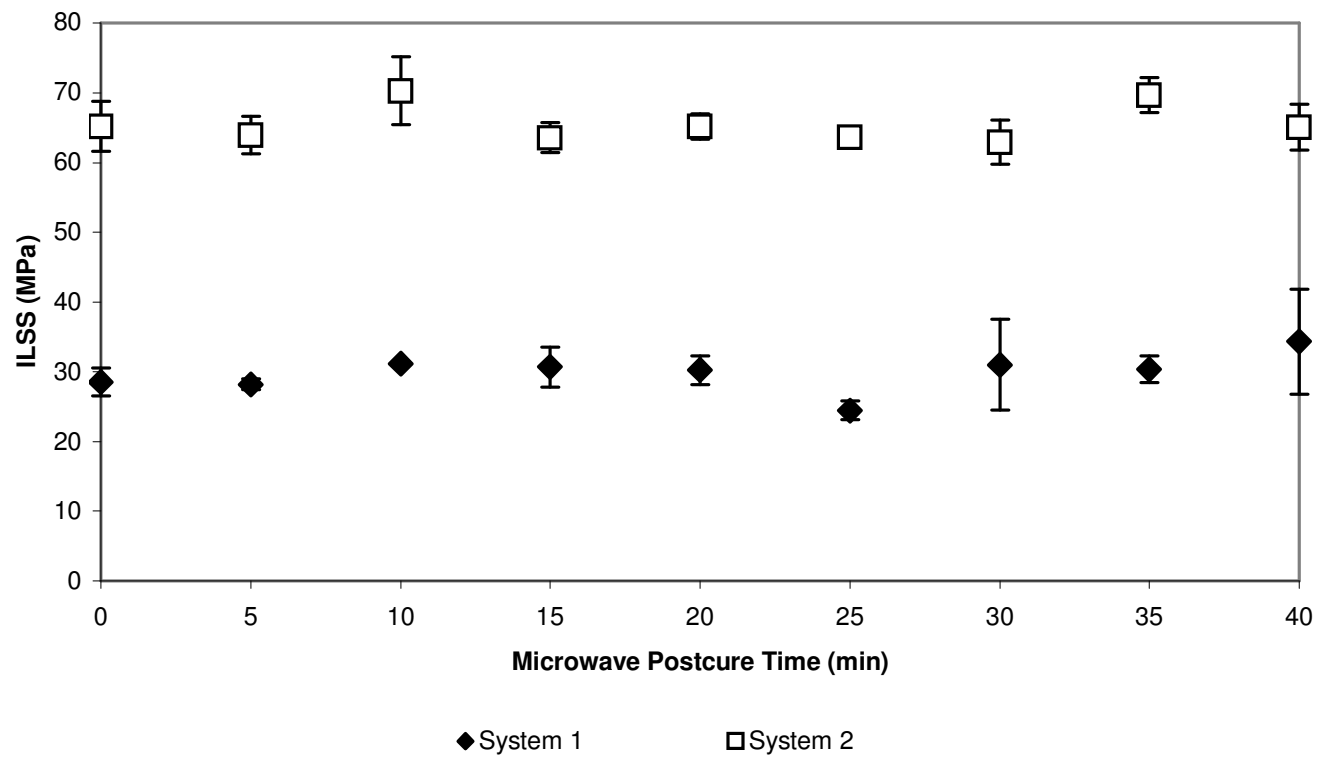

Figure 5. ILSS values for microwave post-cured 16-ply $\left(0 / 90^{\circ}\right)$ System 1 and System 2 composites 


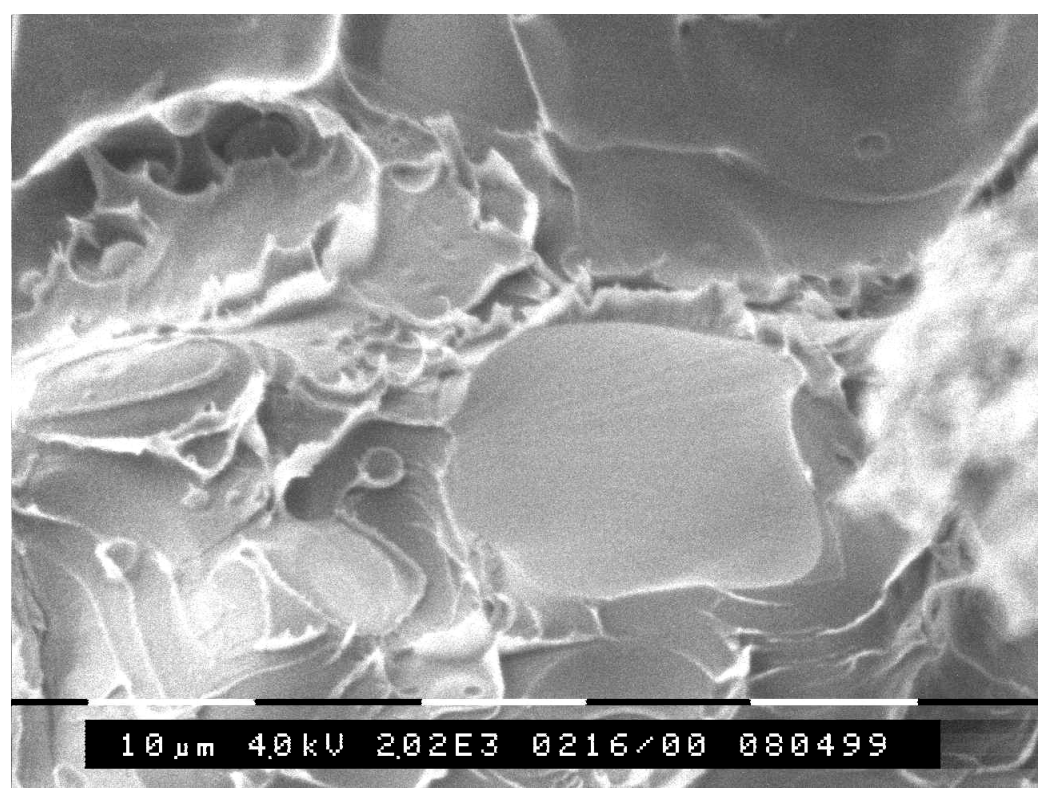

Figure 6. Scanning electron micrograph of the System 1 matrix after thermal curing for 90 minutes at 130 ${ }^{\circ} \mathrm{C}$ and then 2 hours at $180{ }^{\circ} \mathrm{C}$

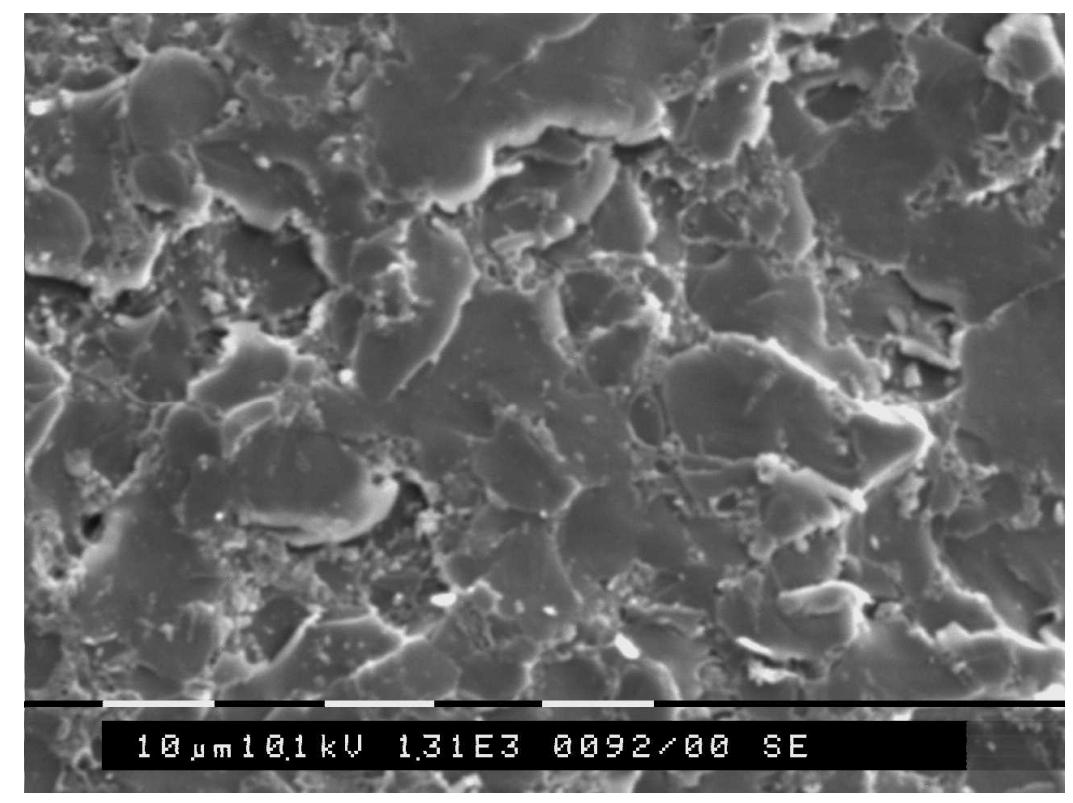

Figure 7. Scanning electron micrograph of the System 2 matrix after thermal curing for 90 minutes at $130{ }^{\circ} \mathrm{C}$ then for and 2 hours at $180{ }^{\circ} \mathrm{C}$ 


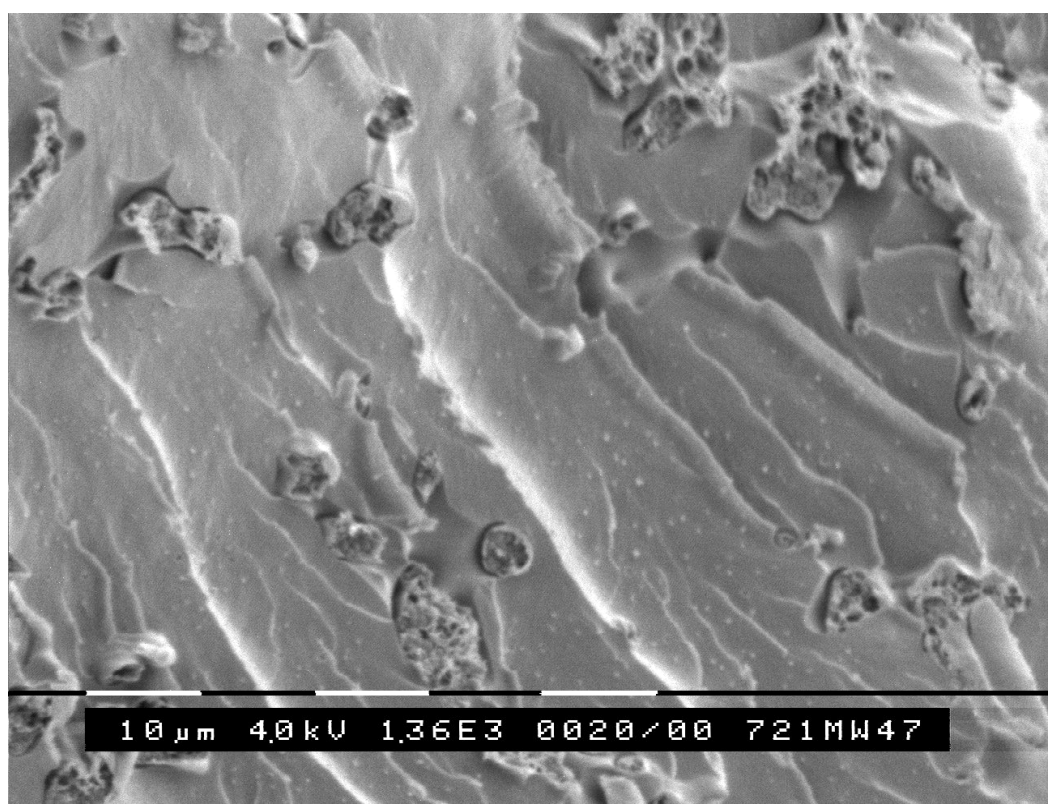

Figure 8. Scanning electron micrograph of the System 2 matrix after microwave cured for 40 minutes

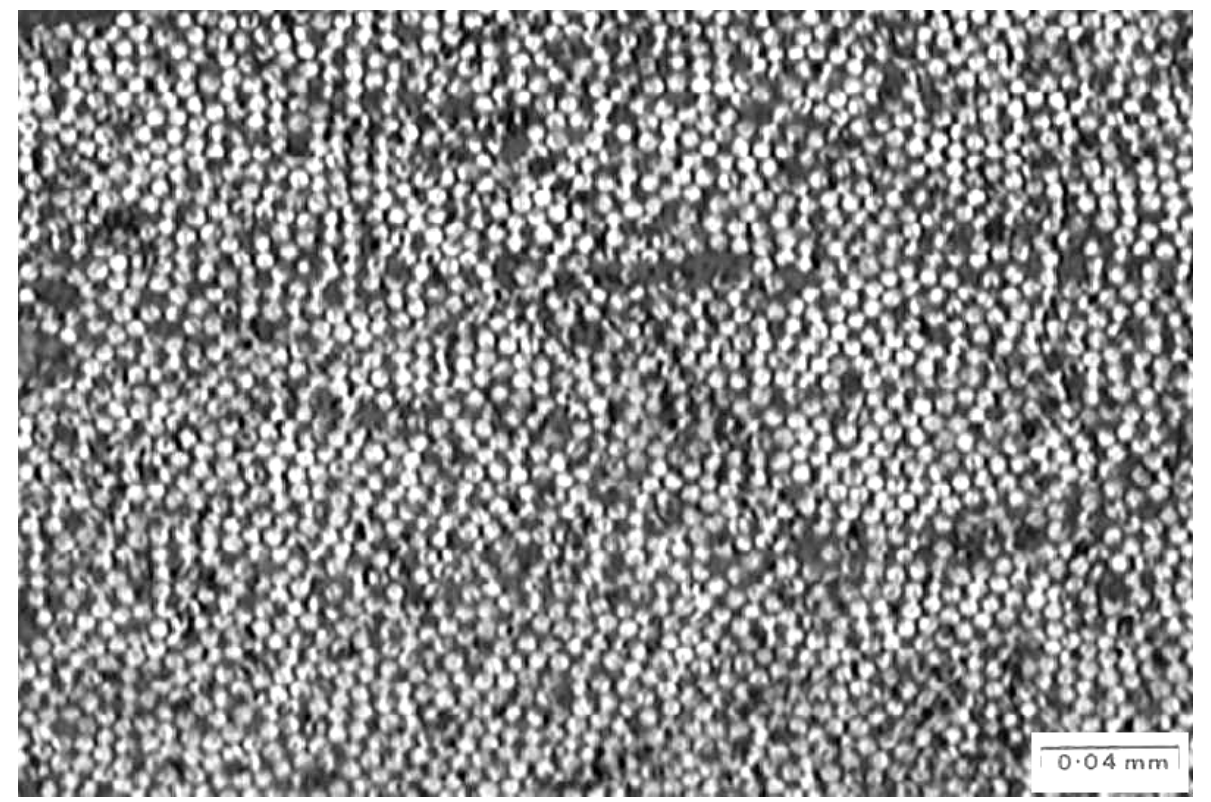

Figure 9. Autoclave cured System 1 composite 


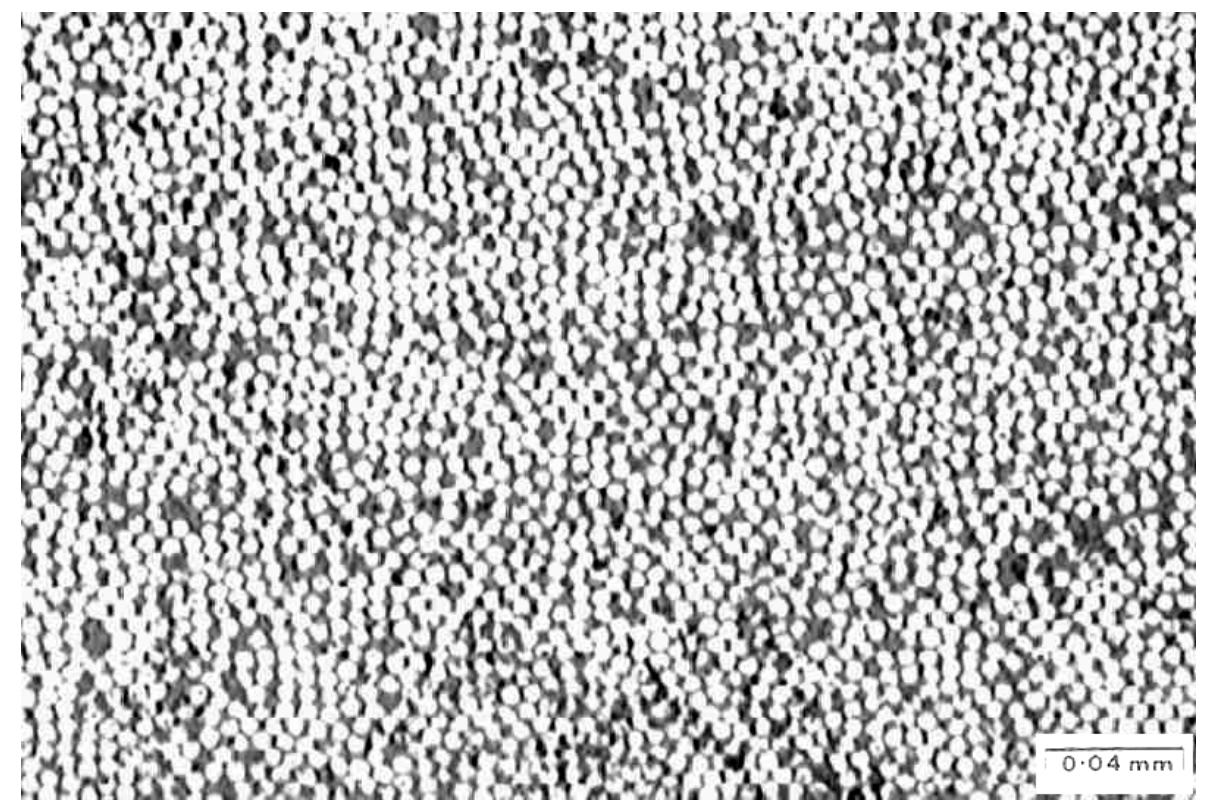

Figure 10. Autoclave cured System 2 composite

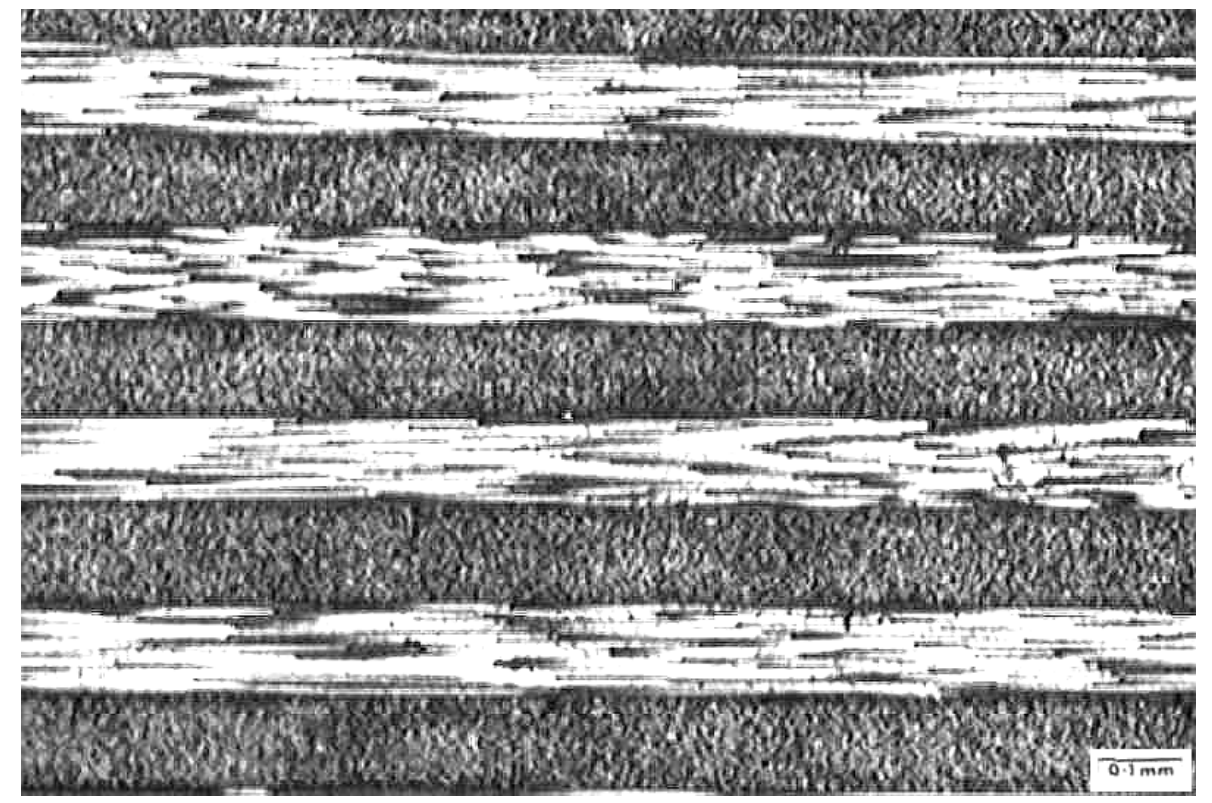

Figure 11. System 2 composite, microwave post-cured for 5 minutes 


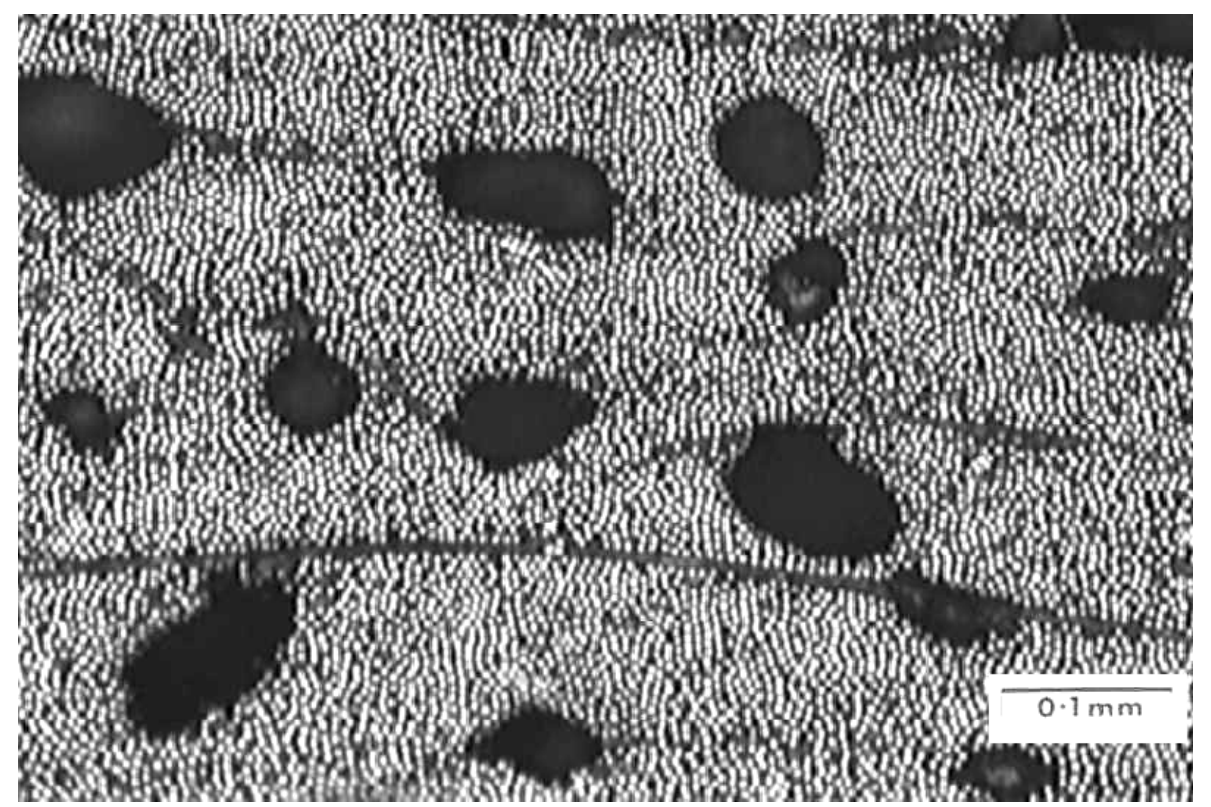

Figure 12. Microwave cured System 1 composite, fibres parallel to radius of turntable

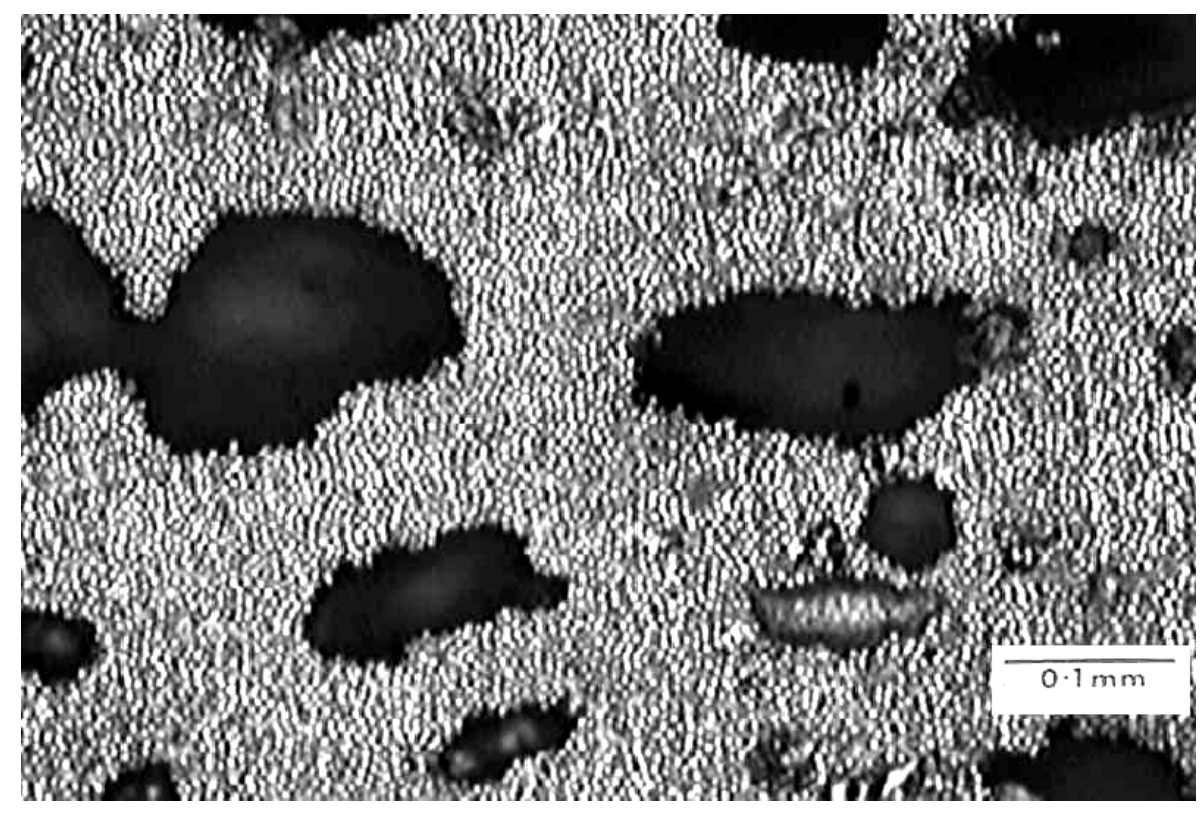

Figure 13. Microwave cured System 1 composite, fibres perpendicular to radius of turntable 


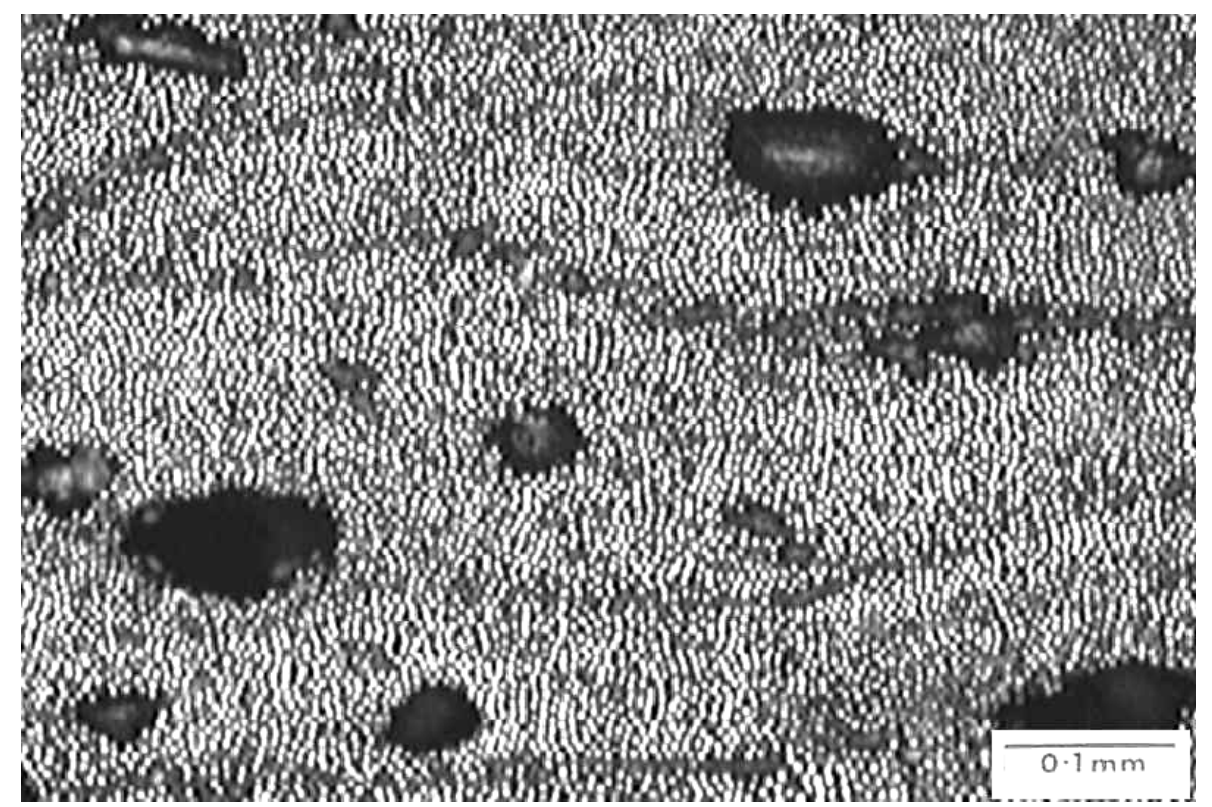

Figure 14. Microwave cured System 2 composite, fibres parallel to radius of turntable

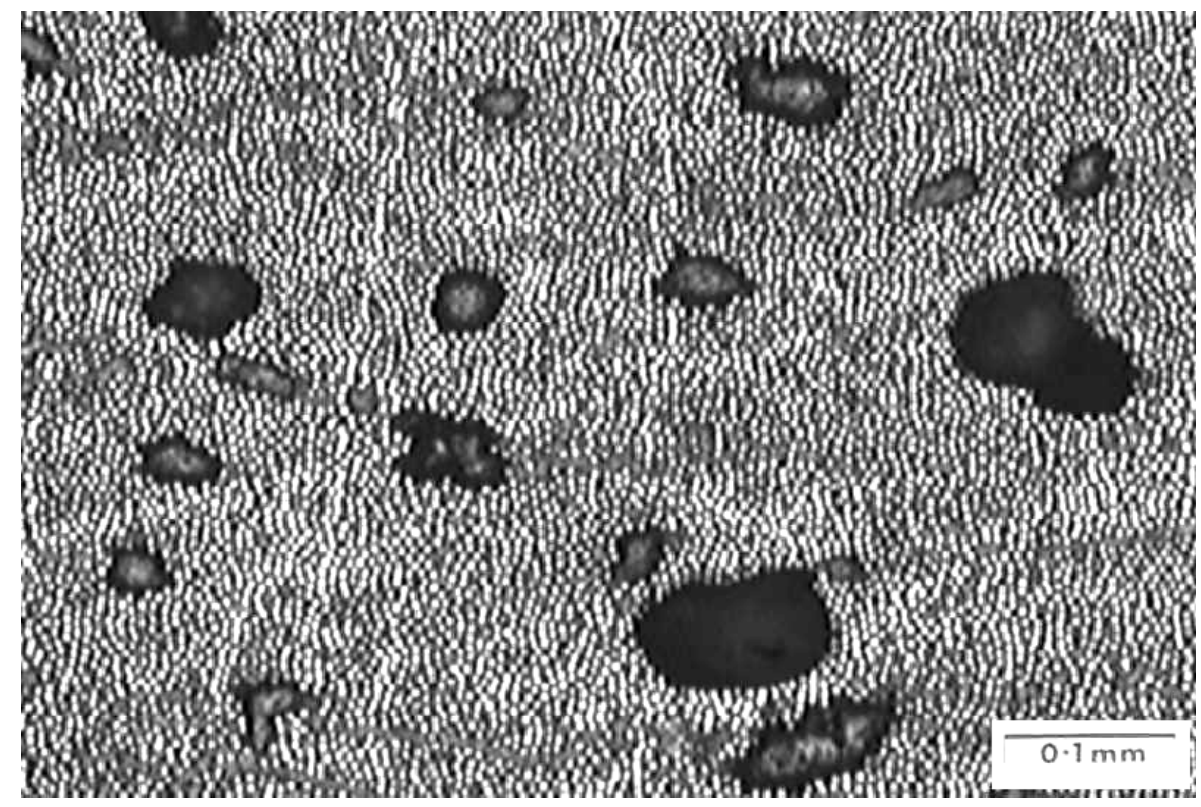

Figure 15. Microwave cured System 2 composite, fibres perpendicular to radius of turntable 


\begin{tabular}{|c|c|c|}
\hline Power setting & Duration power on / s & Duration power off /s \\
\hline 1 & 10 & 70 \\
\hline 2 & 10 & 30 \\
\hline 3 & 20 & 20 \\
\hline 4 & 30 & 10 \\
\hline 5 & On continuously & - \\
\hline
\end{tabular}

Table 1. Relationship between power setting and duration of microwave heating

\begin{tabular}{|l|l|}
\hline $\begin{array}{l}\text { Sample } \\
\text { number }\end{array}$ & Heating Time and Power Setting \\
\hline 1 & 5 min, Setting 3 \\
\hline 2 & 10 min, Setting 3 \\
\hline 3 & 15 min, Setting 3 \\
\hline 4 & 20 min, Setting 3 \\
\hline 5 & 20 min, Setting 3 + 5 min, Setting 4 \\
\hline 6 & 20 min, Setting 3 + 10 min, Setting 4 \\
\hline 7 & 20 min, Setting 3 + 15 min, Setting 4 \\
\hline 8 & 20 min, Setting 3 + 20 min, Setting 4 \\
\hline
\end{tabular}

Table 2. Heating times and power settings for microwave post-cure of partially autoclave cured composites

\begin{tabular}{|c|c|c|c|c|c|c|}
\hline System & $\begin{array}{l}\text { Flexural } \\
\text { modulus with } \\
\text { sample parallel } \\
\text { to the edge of } \\
\text { the turntable/ } \\
\mathrm{GPa}\end{array}$ & $\begin{array}{l}\text { Flexural } \\
\text { modulus with } \\
\text { sample } \\
\text { perpendicular } \\
\text { to the edge of } \\
\text { the turntable/ } \\
\mathrm{GPa}\end{array}$ & $\begin{array}{l}\text { Flexural } \\
\text { strength } \\
\text { with } \\
\text { sample } \\
\text { parallel to } \\
\text { the edge of } \\
\text { the } \\
\text { turntable/ } \\
\text { Gpa }\end{array}$ & $\begin{array}{l}\text { Flexural } \\
\text { strength with } \\
\text { sample } \\
\text { perpendicular } \\
\text { to the edge of } \\
\text { the turntable/ } \\
\text { GPa }\end{array}$ & $\begin{array}{l}\text { Interlaminar } \\
\text { shear } \\
\text { strength with } \\
\text { sample } \\
\text { parallel to the } \\
\text { edge of the } \\
\text { turntable/ } \\
\mathrm{MPa}\end{array}$ & $\begin{array}{l}\text { Interlaminar } \\
\text { shear } \\
\text { strength with } \\
\text { sample } \\
\text { perpendicular } \\
\text { to the edge of } \\
\text { the turntable/ } \\
\mathrm{MPa}\end{array}$ \\
\hline 1 & $117 \pm 6$ & $123 \pm 9$ & $1434 \pm 136$ & $1071 \pm 231$ & $72.2 \pm 5.8$ & $51.9 \pm 7.0$ \\
\hline 2 & $134 \pm 14$ & $101 \pm 12$ & $1075 \pm 277$ & $806 \pm 244$ & $48.3 \pm 12.6$ & $56.5 \pm 26.0$ \\
\hline
\end{tabular}

Table 3. Flexural properties of microwave cured composites 


\begin{tabular}{|c|c|c|}
\hline System & ILSS/MPa at $22{ }^{\circ} \mathrm{C}$ & ILSS/MPa at $81{ }^{\circ} \mathrm{C}$ \\
\hline 1 & $118.2 \pm 3.2$ & $96.1 \pm 2.4$ \\
\hline 2 & $101.5 \pm 2.3$ & $87.4 \pm 0.6$ \\
\hline
\end{tabular}

Table 4. Interlaminar shear strength values for the autoclave cured unidirectional composites measured at 22 and $81{ }^{\circ} \mathrm{C}$

\begin{tabular}{|l|c|}
\hline Type of Composite & Void Content (\%) \\
\hline System 1 autoclave & 0.1 \\
\hline System 2 autoclave & 0.1 \\
\hline System 1 post-cure 5 mins & 1.5 \\
\hline System 1 post-cure 40 mins & 1.4 \\
\hline System 2 post-cure 5 mins & 1.3 \\
\hline System 2 post-cure 40 mins & 1.6 \\
\hline System 1 microwave, parallel & 19.3 \\
\hline System 1 microwave, perpendicular & 19.9 \\
\hline System 2 microwave, parallel & 8.9 \\
\hline System 2 microwave, perpendicular & 12.0 \\
\hline
\end{tabular}

Table 5. Void content measured by image analysis 